\title{
Sitzungen und Mitgliederversammlung online
}

Aufgrund der Absage des Dreiländertreffens (DLT) in Wien werden die Sitzungen der Sektionen und Arbeitskreise samt Wahlen online stattfinden. Auch die Mitgliederversammlung wird online abgehalten. Einladungen mit den Links zu den Sitzungen werden per Mail an die hinterlegten Adressen der Mitglieder versendet.

Das DLT 2022 in Zürich ist für den 30.06.3.07.2022 geplant.

\section{Online-Veranstaltungen}

\section{Mittwoch, 27. Oktober 2021:}

- Mitgliederversammlung Sektion KopfHals, 12:15-13:15 Uhr

- Mitgliederversammlung Arbeitskreis Notfallsonografie, 13:30-15:00 Uhr

- Update-Veranstaltung Sektion Anästhesiologie, 15:15-16:45 Uhr

- Update Treffen Sektion Innere Medizin, 17:00-19:00 Uhr
Donnerstag, 28. Oktober 2021:

- Kursleitertreffen Sektion Radiologie, 09:00-10:00 Uhr

- Mitgliederversammlung Arbeitskreis Bewegungsorgane, 09:15-10:15 Uhr

- Mitgliederversammlung Sektion Radiologie, 10:30-11:30 Uhr

- Stufe-II-Treffen Sektion Innere Medizin, 11:45-13:15 Uhr

- Mitgliederversammlung Arbeitskreis Thoraxsonografie, 13:30-14:30 Uhr

- Mitgliederversammlung Chirurgie, 14:45-16:15 Uhr

- Kursleitertreffen Sektion Anästhesiologie, 16:00-17:30 Uhr

- Mitgliederversammlung Sektion Pädiatrie, 16:30-17:30 Uhr

- Mitgliederversammlung Sektion Gynäkologie und Geburtshilfe, 17:45-19:45 Uhr

\section{Freitag, 29. Oktober 2021}

- Mitgliederversammlung Arbeitskreis Sonografie in Entwicklungs- und Schwellenländern, 8:00-9:00 Uhr

- Mitgliederversammlung Arbeitskreis Ultraschallsysteme, 9:15-10:15 Uhr
- Mitgliederversammlung Sektion Naturwissenschaft \& Technik, 10:30-11.30 Uhr

- Mitgliederversammlung Arbeitskreis Fetale Echokardiografie, 11:45-12:45 Uhr

- Mitgliederversammlung Arbeitskreis Mammasonografie, 13:00-14:00 Uhr

- Stufe-III-Treffen Arbeitskreis Mammasonografie 14:15-15:15 Uhr

- Mitgliederversammlung Arbeitskreis Endosonografie 15:30-16:30 Uhr

- Mitgliederversammlung Arbeitskreis Interventioneller Ultraschall, 16:45-17:45 Uhr

- DEGUM-Mitgliederversammlung, 18:00-19:30 Uhr

Alle Termine werden auch im Veranstaltungskalender der jeweiligen Sektionen und Arbeitskreise auf der Webseite der DEGUM unter www.degum.de veröffentlicht.

Die Mitgliederversammlung der Sektion Anästhesiologie findet am 23. Oktober 2021 um 9:00 Uhr im Auditorium des Sana Klinikums Borna statt. 